\title{
Construction and Thinking of General Course on Information Science and Technology and Informationization in Higher Colleges and Universities
}

\author{
Shuwang Chang, Yan Jing, and Zhun Ye
}

\begin{abstract}
General education is not only a kind of educational philosophy, but also a way of personnel training, aimed at cultivating a person with sound personality, comprehensive and harmonious development integrity. In this paper, the spirit of general education is considered through the philosophy of course construction and teaching, course content organization and forms of teaching. The construction of general course on information science and technology and informationization is actively carried out. Deep thinking and exploration are given on series topics, such as general education philosophy, top-level design on general education curriculum system, and teaching quality of general courses, which ae restraining factors of the curriculum development. Three suggestions are provided for top-level design, including establishing a specialized work organization, absorbing the essence of successful patterns and focus on the reality. In order to guarantee the quality of general curriculum construction, five measures should be taken, which are strengthening management of the curriculum declaration, strengthening process supervision, perfecting assessment and evaluation mechanism, strengthening teaching staff construction and strengthening the management of students.
\end{abstract}

Index Terms-General education, information science and technology and informationization, general course construction, top-level design, quality of teaching.

\section{INTRODUCTION}

General education is a complex and systemic educational engineering and a value education with cohesive social consensus, aimed at cultivating a person with sound personality, comprehensive and harmonious development integrity [1], [2]. Since the beginning of the 1990s, the development of general education has again ushered in its' spring in Chinese higher colleges and universities. Under the leadership of the Ministry of Education, Peking University, Huazhong University of Science and Technology, Fudan University and others have carried out a series of educational reform and exploration on general education [3]. In 2012, Shandong University (Weihai) formally released the guidance of strengthening general education and formally began its' general education curriculum construction and reform. The course of information science and technology

Manuscript received October 10, 2017; revised November 29, 2017. This work was supported in part by the Teaching and Research Fund of Shandong University, Weihai.

Shuwang Chang and Zhun Ye are with the School of Mechanical, Electronic and Information Engineering, Shandong University, Weihai, 264209 China (e-mail: shwchang@sdu.edu.cn, zhunye@sdu.edu.cn).

Yan Jing is with the School of Information and Electrical Engineering, Harbin Institute of Technology, Weihai, 264209 China (e-mail: jingyan@hitwh.edu.cn). and informatization with excellent results was in the first list of general education core curriculum construction, and has been circularly opened for all the liberal arts students in the university. After more than three years of efforts, there are some achievements, and there are some issues worthy of further thinking and resolving.

\section{Philosophy of Course Construction And TeAching}

General education is not only a kind of educational philosophy, but also a way of personnel training [1]. Superior teaching philosophy is just like a beacon in the vast sea, which will correctly guide the construction and teaching of the course. After full investigation and years of efforts, the following philosophy of course construction and teaching has been formed.

\section{A. Focus on General Education}

The purpose of general education is to enable students to integrate the philosophy and thought behind the knowledge, and then strive to become a perfect person. Teachers firmly grasp the essence of general education and bring the spirit of general education [4] into all aspects of course construction and teaching. It is hoped that students will understand the new progress of natural science and engineering and their importance to human society through the general learning about these fields. It will help students to learn a variety of disciplinary methods, cultivate a multidisciplinary perspective, cultivate rigorous and realistic scientific attitude and improve their scientific literacy and engineering awareness.

\section{B. Focus on the Ideas Rather than Skills}

Teachers focus on the important ideas and wisdom to promote the development of information science and technology and informationization, enlightening students' thinking, explaining ways to resolve problems and slightly expounding professional and technical knowledge, so that students will understand the background and motivation of some important ideas, and their important contribution and far-reaching impact, which will help students to improve their abilities to discover, analyze and solve problems from different perspectives.

\section{Systematicness and Novelty}

Each of the eight selected modules in this course is organized based on the historical development process, with important ideas, important changes as the branches and leaves, so that students will not only understand the past and 
present of the revenant information science and technology and informationization, but also know the development, application and impact of some new science and technologies, which will help them both systematically grasp these knowledge and understand them with a developmental perspective.

\section{Adhering to the Student as the Main Body}

Teachers adhere to the principle of students as the main body, and guide students to actively participate in the teaching process by stimulating them to prepare and make presentation on small topics, discussing and answering questions in classroom and other ways, which will not only help students to learn knowledge and broaden the foundation, but also improve their abilities to learn, express and cooperate with others. Based on the edification of fusion of scientific spirit and their existing humanistic spirit, and by studying the correct self-treatment, the correct handing of people and nature, personal and social relations, students have a scientific attitude and humanistic quality, and everyone's sense of responsibility and values can be gradually developed.

\section{E. Transparentizing Teaching Information}

A QQ (free instant messaging software) learning group was created and students in the group can share all the teaching materials. At the same time, students can carry out discussion and ideological communication on teaching content on the network platform, so that the three-dimensional learning of classroom, network and life is realized.

\section{ORganizATION OF COURSE CONTENT}

The main contents of this course are given according to the information processing process, and the key issues are shown in Fig. 1.

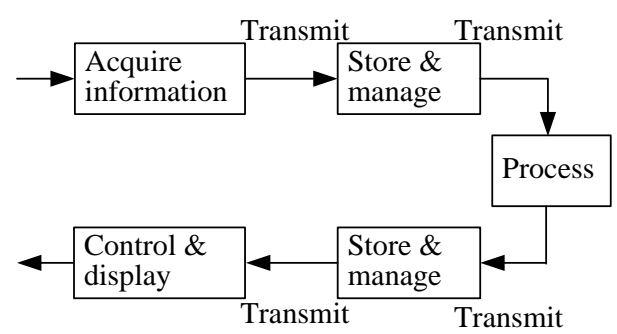

Fig. 1. Modules of information processing system.

The information transmitting can be roughly divided into three main issues, namely communicating, switching and networking. The ultimate goal of researching information science and technology is to put them into application, namely informationizing. At the same time, information science and technology and their applications are evolving, while the source power of the development is scientific and technological innovation. In summary, there are 8 selected modules in the course, including acquiring information, storing, communicating, switching, networking, processing, informationizing and scientific and technological innovation, and they are shown in Fig. 2.

The learning process of the following six modules are basically the same, which are information acquiring, information storing, communicating, information switching, networking and information processing. The teaching concept mainly focus on four issues, including why to do so, how to solve the problem and how to carry it out, what are the important ideas and events and summing up the experience and feelings.

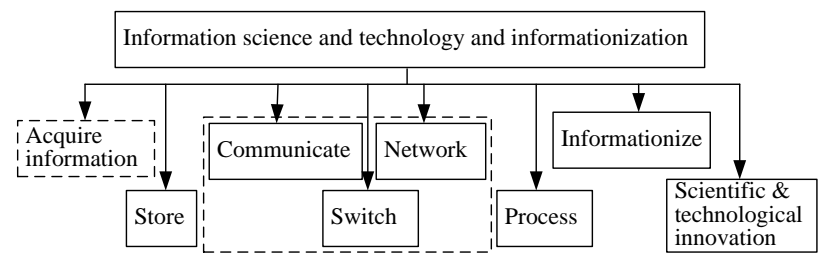

Fig. 2. Modules of the course.

The informationization module mainly talks about the concept of linking theory with practice, and learn the huge promotion and influence of information science and technology on national defense, military, industrial, agricultural and other fields. It guides the students to think some issues, for example, what promoted the application and development of information science and technology, how to look at the changes brought by informationization, and what is the development trend of information science and technology?

Scientific and technological innovation is an eternal topic, and it is a great impetus to promote human society moving forward continuously. General education focuses on cultivating students' abilities and spirits of independent thinking, researching and solving problems and exploring unknown areas [5]. Through the discussion of science and technology innovation module, teachers hope that students can establish certain consciousness of scientific and technological innovation, understand and have some scientific and innovative ways of thinking, so that have certain abilities and spirts of science and technology innovation.

\section{FORMS OF TEACHING}

Teaching is carried out according to the principles of both combining teachers' explaining with students participating in the teaching process and combining learning and discussing on the class with self-learning after class. There are four parts in each module, which are small topics and presentation, commenting and discussing, teacher's systematically explanation and students' thinking and discussing after class.

\section{A. Small Topics Design and Presentation}

Problem based learning [6] is carried out in the course. In the teaching process, teachers take the problems as the starting point for students learning, run them through the whole process of learning, and let students study thinking questions, which can not only stimulate the students' learning initiative and enthusiasm to participate in teaching and expand students' learning experience, but also stimulate students to think actively in the process of solving the problems. Based on the content of each module, first of all, the teacher assigns 4-8 small topics based on the problem in 
advance, and the outline with problems of some topics is given. Secondly, students can also design 1-3 small topics by themselves, however, the content should be decided by both the teacher and students in order to ensure the quality of learning. The duration for each small topic is 5-10 minutes and the form of presentation is free. There are 1-3 students in a group, students from different majors are encouraged to form a team, and they are given 1-2 weeks for preparing the selected topic before the presentation. Students' abilities can be promoted through the process, such as communication, language organization and expression, team cooperation and self-learning. Through their own efforts, students not only understand some of the knowledge and content itself, but also learn the ways to obtain knowledge and can carry out interdisciplinary study, and then can further comprehend some important ideas and methods.

\section{B. Review and Discussion}

There are a few minutes of interactive session after each small topic. Firstly, the teacher makes comments on the topic, give some suggestions to improve quality, correct some errors, or give a few additional explanations, and then guide students to think and exchange ideas.

\section{Systematic Teaching}

Teachers will systematically explain each module based on students' small topics presentation, using multimedia teaching as the main form and other methods as auxiliary. Students will be inspired to learn some important events, ideas and background, many outstanding people and their contributions, so that they can pay close attention to not only the knowledge itself, but also the wisdom behind the knowledge, and then realize the integration and sublimation of ideas in both liberal arts and science.

\section{Thinking after Class}

There will be some questions after finishing the teaching of each module, so that students can both deepen the understanding of the relevant content and make further thinking and discussion.

The flexible and diverse forms of teaching can help students not only learn the knowledge of information science and technology, but also promote their abilities in many aspects and make them comprehend the general laws in the whole field of nature science and technology, the important driving force of the development of information science and technology, and the important contribution of many outstanding people and the inspiration brought by them.

Teachers have already formed the better teaching philosophy, designed the course carefully, and also have won the majority students' high praise. However, during the several years of course construction, they also encountered some problems very worthy of further thinking and urgently need to be solved, some are from the course level, and more are about the factors outside the course itself. Only with a better atmosphere of general education, the general course of information science and technology and informationization can bring out the greatest value and effect.

\section{ESTABLISHING THE CORRECT CONCEPTS OF GENERAL}

\section{AND PROFESSIONAL EDUCATIONS}

General education and professional education should be complementary. English philosopher Whitehead once pointed out that there is no one course only given students ordinary molding, while another course only given them specialized knowledge. Only based on the deep knowing and understanding of both general education and professional education, people can establish a correct concept of them in order to correctly guide and promote the development of general education, and at the same time will let the university education not only meet the needs of people's comprehensive development, but also conform to the trend of social development [2].

\section{A. Specialized Education and Professional Education}

The main goal of specialized education and professional education is basically the same, aimed at cultivating advanced professional personnel with deep knowledge and ability basis in a professional field. Decades of specialized and professional education made an important contribution on the development of national defense, military, economy, science and technology of China. However, the specialized education and professional education focus more on the professional and the deep, rather than the wide. Therefore, along with their development, some deficiencies are gradually appearing, such as overemphasis on science and neglect of arts, narrow professional [1], [7]. Because different trades are separated as non-neighbouring mountains, the too detailed professional division is easy to let people feel that one cloud is enough to eclipse all the sun.

\section{B. General Education}

Although the importance of professional education has been deep-rooted in many people's understanding and general education has not attracted enough attention for most people, it is necessary to carry out general education. The main objectives of general education are to cultivate high-quality talents who will not only have both generous professional knowledge and ability, but have knowledge of the main areas of human knowledge [1]. It is proved that general education in developed countries in Europe and the United States really has played an important role on promoting social development. General education is different from previous quality-oriented education. Quality-oriented education focuses on cultivating students' innovation spirit and practice ability, and promotes students' comprehensive, coordinated and individual development in knowledge, ability, emotion, attitude and values. While general education should be a concept located above the quality-oriented education [1]. Quality-oriented education is more inclined to improve the ideological and quality, while general education is more inclined to improve the quality of culture. Quality-oriented education can be the general knowledge education, while general education is the development of advanced knowledge [2].

\section{Part of the Problems Existing in the Current General Education}

There are some problems in the current general education, such as understanding the surface, generally accepted, verbally emphasized, lack of action, and even holding biased 
to it. For example, a) Some people or management departments have some ambiguity about the philosophy and objectives of general education. b) Because of lack of sufficient argument and reflection, there are some problems, such as carrying out reform in order to reform, lack of scientificalness on curriculum plan, paying more attention to quantity rather than quality and so on. Some people think that carrying out reform on general education is to open more interdisciplinary courses, give more literary influence, and they regard some specialized courses expanding students' knowledge as general curriculum and teach more knowledge of science. In others words, they think that opening a series of general education optional courses is equivalent to carrying out general education. In fact, general education is a kind of talent training mode, and it is a systematic issue. Opening a number of general education optional courses is only an important part of general education, rather than full content of general education. c) There are lack of evaluation mechanism to the opened courses and necessary supervision to the teaching process. d) In some higher colleges and universities, professional courses are given priority when planning the teaching schedule, while general courses often are arranged in the evening or at the weekend.

Education is the foundation of one country, and is a matter related to the overall situation. General education is an important project related to the national education plan and should be given great attention. General education and professional education are like a person's two legs, the better they cooperate with each other, the faster one can run. Both the relevant education departments and higher colleges and universities should work together to alter the traditional fragmented management model [8], and correct some people's misunderstanding on general education, so as to let general education develop healthily.

\section{Strengthening Top-LeVel Design And PlanNing}

General education is superficial if it lacks of ideas, it is empty if it lacks of content, and it won't last for long if it lacks of system guarantee [3]. At the same time, the construction of general education curriculum is not only the construction of a number of independent courses, but also is a systematic project. Therefore, people should make the top-level design with a higher-level vision of development, not only learn from the essence of successful mode, but also focus on their own reality, work out a feasible training program system for general education, and provide system guarantee at the same time.

\section{A. Establishing a Specialized Work Organization}

In the whole education system, general education has an important status and significance, and it is very important to take out a top-level design and planning. Therefore, it is necessary to establish a specialized work organization for general education and gathering a large number of experts with rich teaching experience and interested in education, professors and famous teachers. They should carry out special study and take overall consideration and make plan on general education, so as to not only formulate policies, rules and regulations of general education, but also lead and supervise the construction and reform of general curriculum.

\section{B. Absorbing the Experiences of Successful Patterns}

Based on the study of mature general education in developed countries in Europe and the United States, it is easy to find that they all carry out reforms on general education according to their own reality, and all aim at solving their important social problems. There are some patterns of general education, such as the typical patterns of Columbia University, Chicago University and Harvard University in the United States of America [9], [10]. Because America has its special social background, education system and social values, its goal of general education also has its particularity, and it was proved that the effect was not ideal when carrying out general education in Germany using the pattern of America after World War II [11]. Therefore, no pattern is common, and only the one that suits the situation is the best. Because general education in China is still in the primary stage, using other counties experience for reference is necessary, however, we should not blindly copy some pattern. We should carefully study the background of different successful patterns, the problems that need to be solved and their implementation plan, so as to absorb and use their experiences. At the same time, society is continuously developing, and even if the mature general education in developed countries is also in the process of continuous development and reform, so people should look at the general education in a developmental perspective.

\section{Strengthening Top-Level Design based on Reality}

General education is not only a part of the curriculum, but also a whole concept of education. It is concerned with the harmonious development of people's living world, morality and reason in a whole way of thinking [12]. Therefore, we should not only consider the important issues facing in the country for current and future period of time from the economic and cultural, but also combine a serial of actual factors including the regional characteristics, the objectives of the university, the scale of running a university, the dynamics of students and so on, so as to do well a full investigation and discussion on the architecture and curriculum composition and do a good job of architecture design and a long-term planning of general education from top-level based on the actual situation and focusing on the future development, which will guide the construction of general education in higher colleges and universities as a program of action.

It is the best one and that meets the needs of development of China only when the top-level design of general education is provided based on both the successful and advanced patterns and experiences of foreign countries and Chinese local conditions.

\section{GUARANTEEING CONSTRUCTION QUALITY OF GENERAL CURRICULUM}

The quality of personnel training is the life of higher colleges and universities. The construction quality of general education is related to the realization of the goals of higher education and the overall quality of personnel training, 
therefore, it should be highly concerned by teaching, student management and other related departments, and which have the responsibility and obligation to keep good construction quality of the general curriculum.

\section{A. Strengthening Management of Curriculum Declaration}

It is necessary to carry out the long-term planning and overall consideration on the curriculum. People should pay more attention to the quality rather than quantity, and the communication of liberal arts and science and the cultivation in fusion of scientific spirit and humanistic spirit rather than the enough variety of courses on the surface. The courses' aims, the design of teaching contents and so on, should be strictly examined, which will not only prevent opening some professional courses under the name of general course by reducing difficulty or in a tutorial and introduction nature, but also prevent courses without substantive contents. People should pay more attention to the embodiment of general spirit in contents and the internal logic of structure, preventing contents from being put together arbitrarily. The fundamentality of general education is in what way to pursue knowledge rather than the common education in the sense of knowledge form, that is, it oversteps the specialized knowledge demands in different areas of knowledge and achieves the pursuit of the whole [13]. General education in higher colleges and universities emphasizes in what kind of people and what way to open these courses rather than simply to open a few courses belonging to the general education category. In short, it is necessary to strengthen management on curriculum declaration and guarantee the quality of general curriculum from the beginning.

\section{B. Strengthening Process Supervision}

It is only the first step to strengthen management on curriculum declaration, and more important is to strengthen process supervision. At present, there are not enough attention paid to construction process of general curriculum in some higher colleges and universities. Basically, it is regarded that it is the teachers' responsibility to construct the course after one course passes the declaration. In fact, in a sense, the teaching process is more important and it is more critical to reflect the general spirit. Therefore, it is necessary to guard the teaching process, strengthen supervision and prevent low quality teaching. The teaching of general curriculum should be guaranteed not only on the quantity but also, more important, on the quality.

\section{Perfecting Assessment and Evaluation Mechanism}

The scientific and systematic assessment and evaluation mechanism is an important means to guarantee the quality of general education, and is the guiding mechanism carrying out general education [14]. At present, many higher colleges and universities have not formed a systematic assessment and evaluation mechanism, some of them continuously use the evaluation system of professional curriculum, and some have improved the evaluation system but which is still not enough scientific and systematic. Therefore, people should fully investigate, research and think, give full consideration to the particularity of general education and comprehensively consider a series of factors including the evaluation objectives, contents, methods, participants, use of evaluation results and so on, so as to establish a set of systematic, scientific and practical assessment and evaluation mechanism. According to the policies of promoting construction, reform and management by evaluating, integration of evaluation and construction and focus on construction, the periodic assessment and evaluation of general curriculum should be strengthened, and not only the excellent courses and people should be commended, but also the low-ranked ones should be urged to rectify and reform, all of which will encourage the teachers' enthusiasm, strengthen their sense of responsibility and improve the teaching quality of general curriculum, and ultimately services for the overall strategy of personnel cultivation in higher colleges and universities.

\section{Strengthening Teaching Staff Construction}

In higher colleges and universities, the way and attitude of learning itself of excellent teachers are the most important basis and resource for general education, and any magnificent names of general curriculum are nothing but empty symbols leaving the personality lead of teachers in higher colleges and universities, in this sense, the practice of general education is almost excellent teachers themselves in higher colleges and universities [13]. First of all, the teachers of general curriculum should have general spirit and they should not teach general courses in a specialized way of thinking. They must have to cause themselves to have the live knowledge moreover to have ability to set bridges in the fields of knowledge that has been divided [15]. The strategy of both hands should be taken in order to strengthen the teaching staff construction of general curriculum, namely, not only to attract outstanding teachers to join the general education team, but also to enhance their general cultural background of the existing teachers, guide them to improve their knowledge structure, update the concept of education and encourage them to participate in academic exchanges, taking a refresher course and attending professional training, so as to build a high-level teaching staff of general education. In addition, in order to guide teachers to pay more attention on improving the teaching quality of general curriculum, a set of supporting mechanism of incentives and rewards should be established, which will further improve teachers' enthusiasm of teaching and research.

\section{E. Strengthening the Management of Students}

The center issue of general education in higher colleges and universities is how to guide students to discover new and nobler motives by themselves and construct a different, more humanistic way of life through their studies [13]. It is the fundamental symbol of general education really happened only to fully evoke the individual heart to pursue good things [13]. However, at present many students in higher colleges and universities do not put more energy on the pursuit of knowledge and wisdom and the pursuit of excellence and noble, many of them who are in classroom absence of mind, even some of them are absenteeism. Because of students' strong utilitarian on course selection, some teachers of general curriculum are facing a dilemma on selecting strict teaching and attracting more students. That is to say, if the teacher is strict, the number of students who select the course will be small, and if they want to attract more students, they 
will be forced to reduce the assessment criteria. It is difficult to solve the problem only depending on teachers themselves. Therefore, in order to solve the problem, it is necessary to take unified action for the related management departments of higher colleges and universities and teachers, and they should work together to strengthen the appraisal mechanism for the students. General curriculum is neither a kind of courses regarding students' skipping classes as a normal state, nor a kind of courses allowing students easily obtaining credit without effort.

\section{CONCLUSION}

Information science and technology and informationization is an important general education core course of Shandong University (Weihai). The following philosophy focuses on the course construction and teaching of general education, which includes focusing on general education, focusing on ideas rather than skills, emphasizing on both systematicness and novelty, adhering to the student as the main body and transparentizing teaching information. Eight modules are selected carefully according to the information processing progress and all of them are designed on teaching forms and teaching methods elaboratively. Then some in-depth thinking and discussions were carried out from three aspects detailedly, which are how to establish the correct understanding of general education and professional education, how to do a good job on the top-level design of general education based on the reality, and how to guarantee the construction quality of general curriculum. All of these work will not only help to promote reform of general education but also help to improve the quality of general education in higher colleges and universities.

\section{ACKNOWLEDGMENT}

Shuwang Chang and all co-authors thank for the reviewing experts for their reviews and suggestions!

\section{REFERENCES}

[1] X. M. Chen, "An analysis of some concepts about general education," Journal of Higher Education Management, vol. 27, no. 3, pp. 64-68, March 2006.

[2] H. J. Zhang and Z. T. Sun, "Research review on university general education in China," Research in Higher Education of Engineering, no. 5, pp. 81-88, October 2009.

[3] H. S. Pang and X. H. Huan, "General education in China: Review and expectation," Journal of Higher Education Management, vol. 10, no. 1, pp. 12-19, January 2016.

[4] H. B. Jiang and T. Liang, "Manifestation of general spirit and reform of general education in universities," Educational Research, pp. 95-99, January 2012.

[5] J. B. Li, General Education Theory, Beijing: Higher Education Press, 2012, p. 114
[6] H. C. Li, "Knowledge centeredness of current general education and a new general education approach," Fudan Education Forum, vol. 9, no. 6, pp. 30-35, December 2011.

[7] L. Zhang, "General education reform in China: Achievements, dilemma, and solution," Tsinghua Journal of Education, vol. 35, no. 6, pp. 80-84, December 2014

[8] H. C. Wang and D. B. Xie, "The progress, dilemma and outlet of Chinese general education in the past 20 years," Journal of Xiamen University (Arts \& Social Sciences), General Serial No.232, pp. 21-28, December 2015.

[9] C. H. Qin, "What kind of general education do we need," China University Teaching, no. 11, pp. 17-26, November 2016.

[10] X. Y. Wang and S. S. Cao, "American university general education models, challenges and strategies," China Higher Education Research, no. 4, pp. 17-25, May 2015.

[11] Q. L. Kang, "Reflections on general education in Chinese universities," Jiangsu Higher Education, no. 2, 2009, pp. 78-81, April 2009.

[12] G. B. Xue, "Misunderstanding and turning of specialization in general education," Higher Education Exploration, no. 3, 2014, pp. 35-39, June 2014.

[13] T. F. Liu, "The implication and practicability of university general education," Journal of Higher Education, vol. 33, no. 7, pp. 1-5, July 2012.

[14] H. M. Feng, M. D. Huang, and T. Zuo, "University liberal education teaching quality evaluation system and index design," Education Research, General No. 394, no.11, pp. 24-28, November 2012.

[15] S. L. Ni, "The true meaning, problems and countermeasures of general education," Education Research, General No. 380, no. 9, pp. 94-97, September 2011.

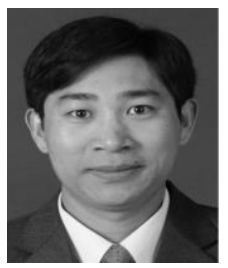

Shuwang Chang was born in Shandong province, China, in 1976. He received the B.E. degree in electronic and information system from Shandong University at weihai in 1999. And received the M.E. degree in circuit and system from Shandong University in 2003. $\mathrm{He}$ is currently a Ph.D. candidate communication and information system at Shandong University.

$\mathrm{He}$ is a lecturer in School of Mechanical, Electronic and Information Engineering at Shandong University, Weihai. His research focuses on the routing technology of wireless sensor networks.

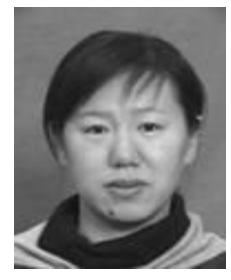

Yan Jing was born in Heilongjiang province, China, in 1976. She received the B.E. and M.E. from Dalian Jiaotong University, Dalian, China, in 1999 and 2003 , respectively. She received the Ph.D. degree in the School of Astronautics from HIT in 2017.

She is a lecturer in the School of Information and Electrical Engineering at HIT at Weihai. Her research focuses on array signal processing and blind signal processing.

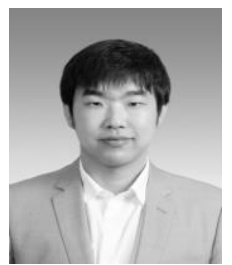

Zhun Ye was born in Heilongjiang province, China, in 1981. He received his B.E., M.E. and Ph.D. degree in communication engineering from Harbin Institute of Technology, China, in 2004, 2006 and 2013, respectively.

He is currently a lecturer at Shandong University, Weihai, China. His current research interests include broadband wireless communications, multiple input multiple-output (MIMO) technology, and cloud radio access networks (Cloud-RAN). 